\title{
A Study on the Behavior of Bubbles Trapped in the In-Mold Coating Process
}

\author{
Phuong NguyenThi1,2, Arim Kwon1, Yeong-eun Yo01,2,\#, and Jae Sung Yoon1,2 \\ 1 Korea Institute of Machinery and Materials (KIMM), 156 Gajeongbuk-Ro, Yuseong-Gu, Daejeon 305-343, Korea \\ 2 University of Science and Technology (UST), 217 Gajeong-Ro, Yuseong-Gu, Daejeon, Korea \\ \# Corresponding Author / E-mail: yeongeunyoo@gmail.com, TEL: +82-42-868-7883, FAX: +82-42-868-7149
}

(Manuscript received: Oct, 8, 2012 / Revised: Nov, 30, 2012 / Accepted: Dec, 3, 2012)

This paper investigates the behavior of bubbles trapped in the in-mold coating (IMC) process. Silicon oil with different viscosity, 100, 150, 200, 300 and 400cps, was selected instead of the coating materials. To observe the flow front inside, a special mold was designed, where front plate was made of transparent material (acrylate). The overall size of front plate was $150 \mathrm{~mm} \times 120 \mathrm{~mm}$. Mold gate location can be changed from up to down. Four heaters were used to investigate the effectiveness of temperature. The results show that silicon viscosity, mold gate location and mold temperature play an important role on the appearance of bubbles trapped in IMC process.

KEYWORDS: In-mold coating (IMC), flow behavior, coating materials, bubbles trapped, silicon oil, gate location, stable.

\section{Introduction}

Coating is an essential process for the final products. It plays an important role in improving the surface properties of products, such as appearance, adhesion, wettability, and resistance against corrosion, wear and scratch ${ }^{(1)}$. There are a lot of coating technologies, such as chemical vapor deposition, physical vapor deposition, spraying, painting, optical coating, spin coating, in-mold coating (IMC), and so on ${ }^{(2-4)}$. Among them, in recent years, IMC process is a promising technology, which is environmentally friendly and expected to replace some conventional technologies, such as the painting, or spraying for the products from the injection molding process ${ }^{(5 \sim 6)}$. And some studies have also been done on the double injection molding process, which are very similar to the in-mold coating process ${ }^{(7)}$. However the acceptance of IMC as an alternative method to expensive painting process will depend upon the surface quality and adhesion of the substrate.

Fig. 1 is a schematic of all stage of injection molding/ in-mold coating (IM/ IMC) process of thermoplastic part. In injection molding/ in-mold coating (IM/IMC) can be defined as the combination of injection molding and in-mold coating processes. Injection molding process, in general, consists of filling, packing, solidification by cooling and ejecting. But in the IM/IMC process, IMC process is added just before ejecting part from the mold. The IMC process for plastic articles mainly consists of three stages: filling of thermoset resin, packing and curing ${ }^{(8-9)}$. In filling stage, first, the mold is slightly opened, and then a thermoset resin is introduced into the mold cavity until it reaches the end of the mold. Next, during the packing stage, more resin is injected until the mold cavity is fully filled while the mold is closed again. Finally, in the curing stage, the thermoset coating resin is solidified by a chemical reaction.

For the last decade, various studies have been made to investigate the flow behavior of coating materials in the mold. Good understanding on the characteristics of the flow pattern can help to find out a optimal process conditions to improve the surface qualities of molded products. However, it is very hard to control the flow characteristics in IMC process. Recently, simulation researches with various parameters have been made to study the flow characteristics of coating material during IMC process. It was found that the flow was more uniform at fast filling and cooling condition than slow filling and cooling condition ${ }^{(10)}$. Another group of researchers have monitored the flow front of coating resin in the mold to find out that coating thickness, viscosity of coating material, injection speed, temperature and gate location are important parameters in IMC process ${ }^{(11)}$. In this study, moreover, it was concluded in common that gravity and surface tension are two most significant factors in deciding the flow characteristics including flow shape, filling time of flow pattern. Bubbles, however, one typical flow problem which usually happened in IMC process, was not given a lot of attention by researchers. There were some researchers studying on the characteristic of bubbles including bubble diameter, bubble age, bubble direction and so on ${ }^{(12 \sim 16)}$. Furthermore, until now, there was limited study on the source of bubbles in the IMC process. According to some previous researches, there are two main reasons of bubbles in 
IMC process, where bubbles may be trapped in the mold during the injection process or they may be generated in the resin supplying unit.

This study focuses on the bubbles which are trapped in the IMC process. It is important to determine the source where the trapped bubbles come from in order to figure out the bubble problems and optimize the IMC process. In this study, it has been investigated that the appearance of trapped bubbles could be controlled by IMC process condition, including viscosity of coating resin, injection gate location, and mold temperature.

\section{Experiments}

\subsection{Experimental setup}

Silicon oils with different viscosity from Shin-Etsu Silicone Korea Co., Ltd, were used as model coating materials. Peristaltic pumping machine, Thermo Scientific FH100, was used to inject silicon oil into the mold cavity. A schematic of test mold is shown in Fig. 2. For simple analysis, the mold was divided into two parts (Fig. 2a). Each heater can be heated up to $500^{\circ} \mathrm{C}$, with $1^{\circ} \mathrm{C}$ of resolution. Mold gate, where the silicon oil is injected into the mold cavity, is $2 \mathrm{~mm}$ in diameter and connected to the supplying tube. Poly Methyl Methacrylate (PMMA) was selected for front plate of the mold due to its transparency and high modulus up to about $90^{\circ} \mathrm{C}$ which is higher than typical temperature for curing in IMC process ${ }^{(17)}$. The overall size of the front plate was $150 \times 120 \mathrm{~mm}^{2}$ (Fig. 2b). Mold gate location can be changed from upper to lower.

Table 1 Experimental setup conditions.

\begin{tabular}{|c|c|}
\hline Parameter & Experimental setup \\
\hline Viscosity $(\mathrm{cps})$ & $100,150,200,300,400$ \\
\hline Coating thickness $(\mathrm{mm})$ & 0.3 \\
\hline Pumping speeds $(\mathrm{rpm})$ & 5 \\
\hline Mold temperature $\left({ }^{\circ} \mathrm{C}\right)$ & $25,50,70$ \\
\hline Gate location & Upper (U), Lower (L) \\
\hline
\end{tabular}

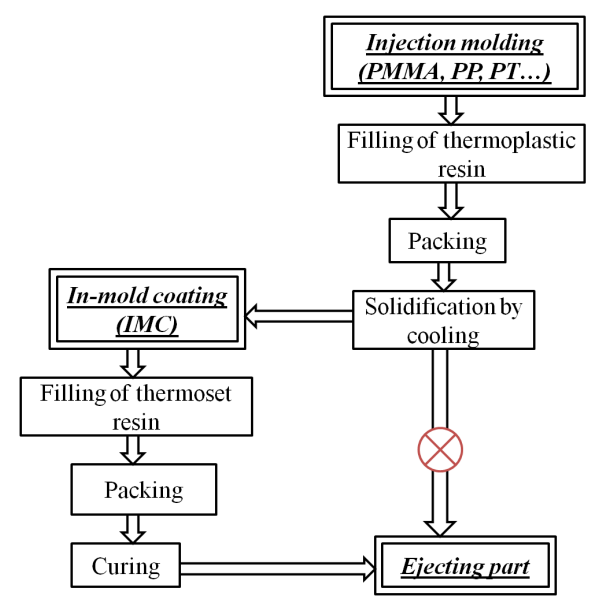

Fig. 1 A schematic of Injection molding/ In-mold coating (IM/IMC) process of thermoplastic part.
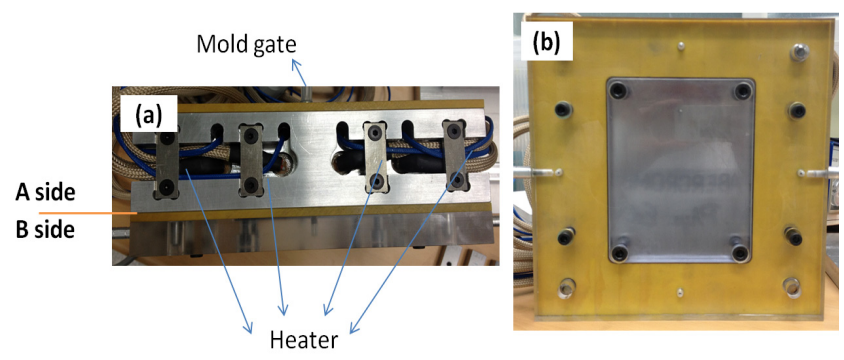

Fig. 2 Test mold; (a) top view, (b) front view.

\subsection{Experimental procedure}

First, before connecting to the mold gate, the tubes in the test were fully filled with silicon oil to eliminate the bubbles, which may exist inside the tube at start-up. Then, the tube was connected to the gate of the mold. And then, the pumping parameters including pumping speed, pumping direction were set up carefully before starting the test. The flow was recorded using camcorder Sanyo Xacti HD1010.

Experimental setup conditions are shown in Table 1. Coating thickness of $0.3 \mathrm{~mm}$ and pumping speed of $5 \mathrm{rpm}$ were set for all experiments. The experiments were done with various viscosities of silicon oil; 100cps, $150 \mathrm{cps}, 200 \mathrm{cps}$ and $300 \mathrm{cps}$. Then, the experiments were also done at different gate location (upper and lower to investigate gravity effect). We investigated the appearance of bubbles which are trapped at different temperature of the mold $\left(25^{\circ} \mathrm{C}, 50^{\circ} \mathrm{C}\right.$, and $70^{\circ} \mathrm{C}$ ) to find out the conditions in which bubbles maybe trapped or not.

\section{Results and discussions}

\subsection{Flows in the mold for various viscosities}

Experiment results for various viscosities are summarized in Table 2. The results indicated that there was no bubble trapped when silicon oil with high viscosity (200cps, and $300 \mathrm{cps}$ ) was injected into the mold. The flow behaviors of silicon oil with various viscosities are seen in Figs. 3, 4 and 5 which show that the flow changed much with the viscosity. The flow was more uniform and stable for higher viscosity. For lower viscosity, 100cps and 150cps (Figs. 3 and 4), the gravity force becomes more dominant than the surface tension and viscosity. Since gravity force has same direction with the flow, it makes the silicon oil accelerates and reaches the bottom of the mold first before it reaches the side of the mold. For this reason, it makes the flow unstable and creates complicated interface between silicon oil and air inside of the mold, to have more chances for air trap because some part of flow front merge together. However, when the viscosity increases, viscous force becomes more dominant than gravity force (Fig. 5). This results in more round, stable and parabolic because the flow is governed by pressure gradient rather than gravity. Therefore, as predicted, there was less bubble trapped in the flow for more viscous resin (Fig. 5). Consequently, for less viscous resin, the flow is accelerated downward strongly by the gravity force, so that the shape 


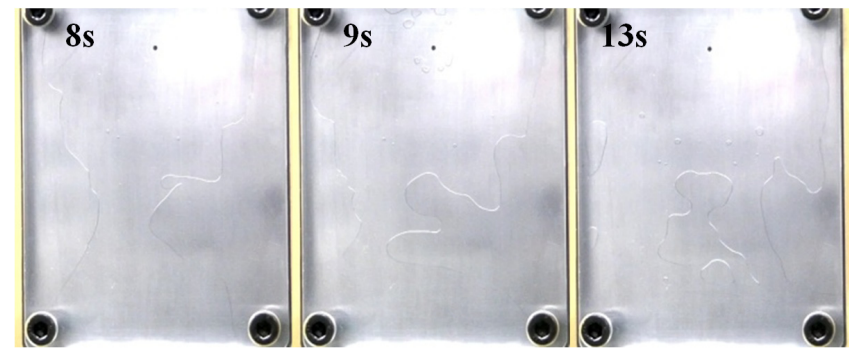

Fig. 3 Flow pattern of silicon oil with viscosity of $100 \mathrm{cps}$ in the mold, upper gate location.

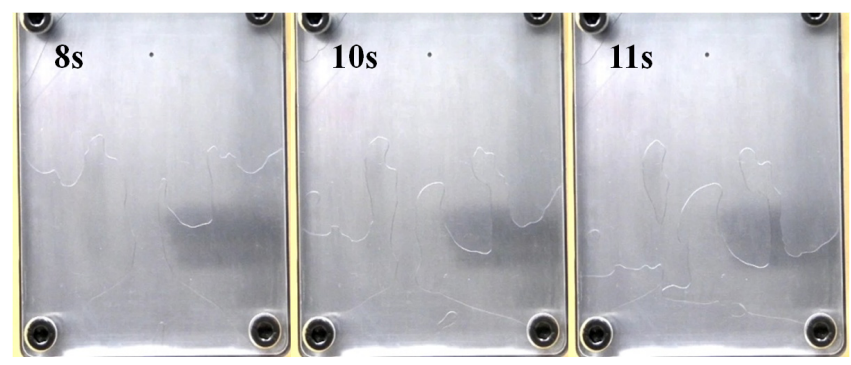

Fig. 4 Flow pattern of silicon oil with viscosity of $150 \mathrm{cps}$ in the mold, upper gate location.

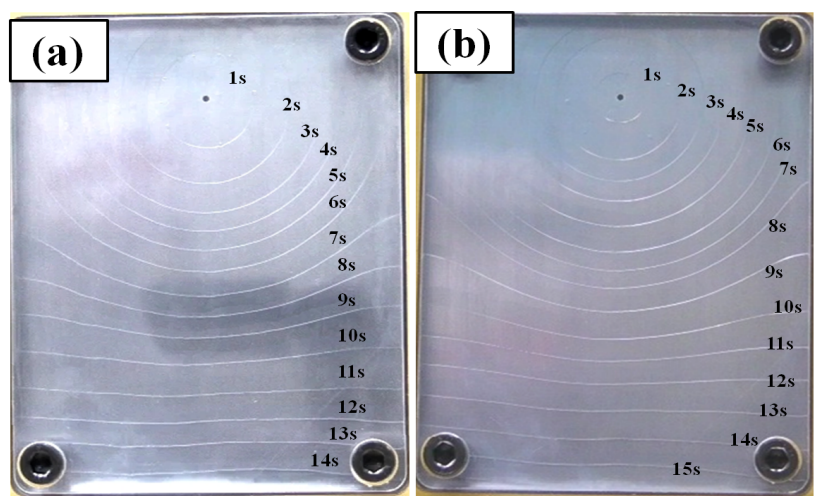

Fig. 5 Flow pattern of silicon oil with viscosity of (a) 200cps, and (b) $300 \mathrm{cps}$ in the mold, upper gate location.

Table 2 Results of the appearance of bubbles trapped in the mold for various viscosities, upper gate location.

\begin{tabular}{|c|c|c|c|c|}
\hline & No.1.1 & No.1.2 & No.1.3 & No.1.4 \\
\hline Viscosity (cps) & 100 & 150 & 200 & 300 \\
\hline Mold temperature $\left({ }^{\circ} \mathrm{C}\right.$ ) & \multicolumn{4}{|c|}{25} \\
\hline Gate location (Upper,Lower) & \multicolumn{4}{|c|}{ Upper (U) } \\
\hline Results (Bubble trapped) & Yes & Yes & No & No \\
\hline
\end{tabular}

of the flow front becomes complex and non-uniform along the flow front line. This could be one of the major reasons explaining the appearance of bubbles trapped at low viscosity in the mold in IMC process.
Table 3 Results of the appearance of bubbles trapped in the mold for various viscosities, lower gate location.

\begin{tabular}{|c|c|c|c|c|}
\hline & No.2.1 & No.2.2 & No.2.3 & No.2.4 \\
\hline Viscosity (cps) & 100 & 150 & 200 & 300 \\
\hline Mold temperature $\left({ }^{\circ} \mathrm{C}\right)$ & \multicolumn{4}{|c|}{25} \\
\hline Gate location (Upper, lower) & \multicolumn{4}{|c|}{ Lower (L) } \\
\hline Results (Bubble trapped) & No & No & No & No \\
\hline
\end{tabular}

\subsection{Flows in the mold for different gate location}

In addition to the experiment in part 3.1 with upper gate location, the test has been also done with lower gate location. Results of the appearance of trapped bubbles are shown in Table 3. It indicated that there was no trapped bubble in the mold when the mold gate was located lower part of mold which can be explained with more uniform and stable flow due to the opposite direction between the flow and the gravity. The flow patterns of silicon oil with viscosity of $100 \mathrm{cps}$ for different gate location (upper and lower) are shown in Fig. 6. It can be seen that the flow pattern changed a lot for different gate location, which means, gravity force is more dominant than surface tension and viscosity. That is the reason for the difference of flow patterns with respect to gate location for low viscosity of silicon oil. Since the mold gate was located downward, the front line was well formed, there will be less chance for air to be trapped by merging up two split flow fronts during the filling stage, which is more expected for the upper gate location.

\subsection{Flows in the mold for various temperatures}

To investigate the effect of temperature on the appearance of trapped bubble, the mold was heated up to $50^{\circ} \mathrm{C}$ and $70^{\circ} \mathrm{C}$ as well. From the experiment results in Table 4, we found that the bubbles appeared for higher temperature $\left(50^{\circ} \mathrm{C}\right.$ and $\left.70^{\circ} \mathrm{C}\right)$ of mold while no bubble was trapped for room temperature. This is because viscosity of silicon oil decreases as the temperature of oil increases and a similar result can be obtained as in chapter 3.1.
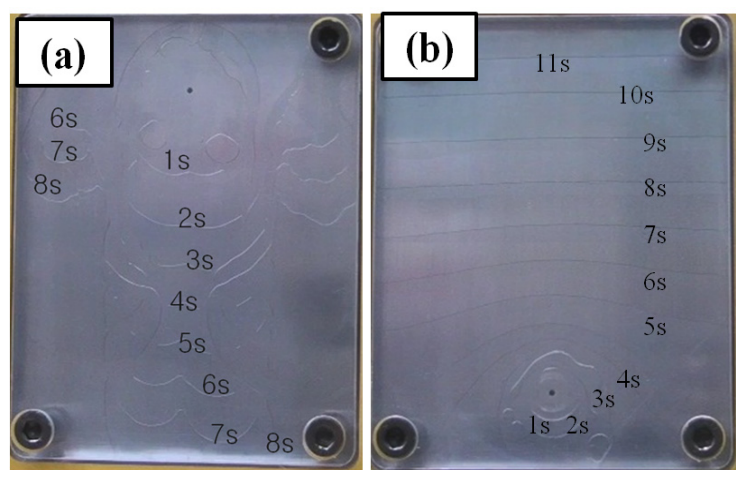

Fig. 6 Flow pattern of silicon oil with viscosity of $100 \mathrm{cps}$ with different gate location; (a) upper gate location, (b) lower gate location. 
Table 4 Results of the appearance of bubbles trapped in the mold for various temperatures.

\begin{tabular}{|c|c|c|c|}
\hline & No.3.1 & No.3.2 & No.3.3 \\
\hline Viscosity (cps) & \multicolumn{3}{|c|}{400} \\
\hline Mold temperature $\left({ }^{\circ} \mathrm{C}\right)$ & 25 & 50 & 70 \\
\hline Gate location (Upper, lower) & \multicolumn{3}{|c|}{ Upper (U) } \\
\hline Results (Bubble trapped) & No & Yes & Yes \\
\hline
\end{tabular}

Test results at different temperature are shown in Fig. $7\left(50^{\circ} \mathrm{C}\right)$ and Fig. $8\left(70^{\circ} \mathrm{C}\right)$. For the mold of $50^{\circ} \mathrm{C}$, the flow moved steadily toward the bottom of the mold with stable and parabolic flow front end, which had little bubbles after the test (Fig. 7). However, for the higher temperature $\left(70^{\circ} \mathrm{C}\right)$, the flow front was complex and very unstable, which was similar to the results for the resin with low viscosity (see Figs. 3 and 4).

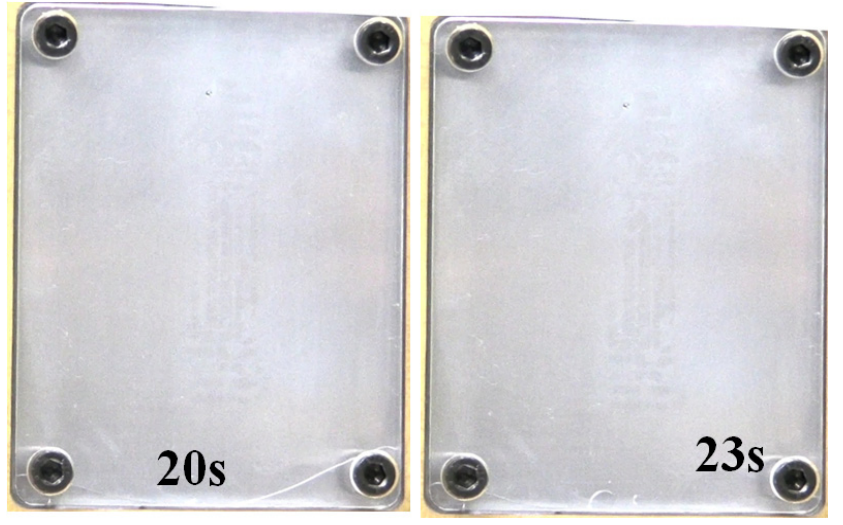

Fig. 7 Flow pattern of silicon oil for $50^{\circ} \mathrm{C}$ of mold temperature (viscosity of silicon oil at room temperature: $400 \mathrm{cps}$ ).

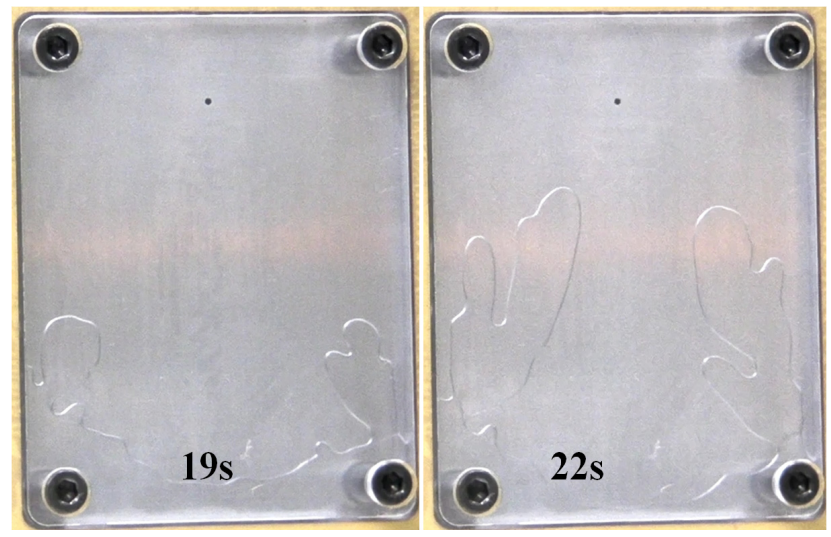

Fig. 8 Flow pattern of silicon oil for $70^{\circ} \mathrm{C}$ of mold temperature (viscosity of silicon oil at room temperature : $400 \mathrm{cps}$ ).

\section{Conclusions}

The results of this study can be summarized as follows.

(1) There will be more chance for bubbles to be trapped when using a coating resin with low viscosity.

(2) Trapped bubbles can be minimized by the location of gate.

(3) Coating at high temperature can be a reason for trapped bubbles.

We could figure out the major parameters for bubble formation in in-mold coating (IMC) process, which are gate location, gravity and oil temperature. We expect this study may be used to prevent the bubble problems in the IMC process.

\section{ACKNOWLEDGEMENT}

This study was supported by the project from the Ministry of Knowledge and Economy of Korean government (project No. : 10040061)

\section{REFERENCES}

(1) Licari, J. J., 2003, Coating Materials for Electronic Applications: Polymers, Processes, Reliability, Testing, William Andrew Publishing, Elsevier, Norwich, NY.

(2) Cabrera-Rios, M., Castro, J. M., and Campbell, C. A. M., 2001, "Multiple Quality Criteria Optimization in Reactive In-mold Coating (IMC) with a Data Envelopment Analysis Approach," Polymer Eng. Sci., Vol. 22, No. 5, pp. 305 340.

(3) Castro, J. M., Cabrera-Rios, M., and Campbell, C. A. M., 2004, "Modelling and Simulation in Reactive Polymer Processing," Modelling Simul. Mater. Sci. Eng., Vol. 12, No. 3, pp. S121 S149.

(4) Castro, J. M., and Grifftith, R. T., 1990, "Mathematical Molding of the In-mold Coating Process," Polymer Eng. Sci., Vol. 30, No. 2, pp. 677 683.

(5) Cabrera-Rios, M., Castro, J. M., and Campbell, C. A. M., 2001, "Multiple Quality Criteria Optimization in Reactive In-mold Coating with a Data Envelopment Analysis Approach II: A Case withmore than Three Performance Measures," Polymer Eng. Sci., Vol. 24, No. 4, pp. 435 450.

(6) Zuyev, K. S., Chen, X., Cabrera-Rios, M., Castro, J. M., and Straus, E. J., 2001, "In-mold Functional Coatings of Thermoplastic Substrates: Process Modeling," J. Inject. Mold. Tech., Vol. 5, No. 2, pp. 80 97.

(7) Hong, M., Lee, J., and Shin, S., 2011, "A Study on the Improvement of Double Injection-molding Keypad Process," $J$. Manufact. Eng. Tech., Vol. 20, No. 5, pp. 659 665.

(8) Bhagavatula, N., and Castro, J. M., 2007, "Modelling and Experimental Verifiation of pressure prediction in the in-mold 
coating (IMC) process for injection moulded part," Modelling Simul. Mater. Sci. Eng., Vol. 15, No. 2, pp. 171 189.

(9) Chen, X., Bhagavatula, N., and Castro, J. M., 2004, "In-mold Coating (IMC) Process for Thermoplastic Parts," AIP Conference Proceedings, Vol. 712, No. 1, pp. 174 179.

(10) Lee, H. S., Kim, D. M., and Yoo, Y. G., 2012, “A study on the Flow Characteristics of Coating Materials During In-mold Coating Processes," Proc. KSMTE Spring Conf., p. 101.

(11) Yoo, Y. -E., Phuong. N. T., Kwon, A. R., Chang, S. H., and Choi, D. -S., 2012, “An Experimental Study on the Flow in the In-mold Coatng Process," Proc. KSMTE Spring Conf., p. 98.

(12) Youn, J. R., and Park, H., 1999, "Bubble Grow in Reaction Injection Molded Parts Foamed by Ultrasonic Excitation," Polymer Eng. Sci., Vol. 39, No. 3, pp. 457 468.
(13) Spence, A. G., and Crawford, R. J., 1996, "The Effect of Processing Variables on the Formation and Removal of Bubbles in Rotationally Molded Products," Polymer Eng. Sci., Vol. 36, No. 7, pp. 993 1009.

(14) Cano, C. I., Clark, M. L., Kyu, T., and Pipes, R. B., 2007, "Modelling Particle Inflation from Poly (amic acid) Powdered Precursors," Polymer Eng. Sci., pp. 617 626.

(15) Chen, X., Feng, J. J., and Bertelo, C. A., 2006, "Plasticization Effects on Bubble Growth during Polymer Foaming," Polymer Eng. Sci., Vol. 46, No. 1, pp. 97 107.

(16) Favelukis, M., 2004, "Dynamic of Foam Growth: Bubble Growth in a Limited amount of Liquid," Polymer Eng. Sci., Vol. 44, No. 10, pp. 1900 1906.

(17) Wikipedia, n.d. viewed 7 September 2012, <http://en.wikipedia. org/wiki/Poly(methyl_methacrylate)>. 